\title{
Correspondence
}

The Editor,

Journal of Glaciology

SIR,

\section{Bowling mermaids; or, How do beach ice balls form?}

River, lake and sea ice appears in many forms and structures, reflecting the variety of conditions under which it is formed. The river Weser estuary, located on the North Sea coast in northern Germany, has rarely been the stage for ice formation in the past few decades. For this reason, it was very exciting for members of the glaciology section at the Alfred Wegener Institute for Polar and Marine Research in Bremerhaven to observe strange ice features just a stone's throw away from the institute on the sandy Weser beach in the first week of January 2003 (Fig. 1).

Numerous ice balls were located at the uppermost tidal line (Fig. 2). The total number was estimated to be around 500; they were aligned in several rows, with the uppermost rows being partly buried in thin ice platelets. Although they were the size of footballs, they were relatively lightweight and fragile. When some of them were smashed, they were seen to consist of two layers: the core was made up of clear ice or frozen slush, while sediment-rich solid ice formed the outer shell. First ideas about their provenance included hail of abnormal size washed ashore, or the leftovers of an epic snowball fight. Others were of the opinion that mermaids must have been at play in the cold weather, bowling at the shore.

Only a little information is available on ball ice (USHO, 1952) and slush balls (IAHR, 1980). Whereas ball ice is described as small spheres of sea ice $<10 \mathrm{~cm}$ in diameter, which are soft and spongy without a distinguishable internal structure, slush balls are defined as an extremely compact accretion of snow, frazil ice and ice particles. Since the presence of ice balls with a distinct internal structure seems to be a rare feature, we investigated their properties and origin with a small series of measurements.

Five balls were collected to determine different properties in the cold laboratory at $-25^{\circ} \mathrm{C}$. They had a near-spherical shape, with a circumference of $73 \pm 2 \mathrm{~cm}$. The surface was smooth but irregular, with undulations on the order of

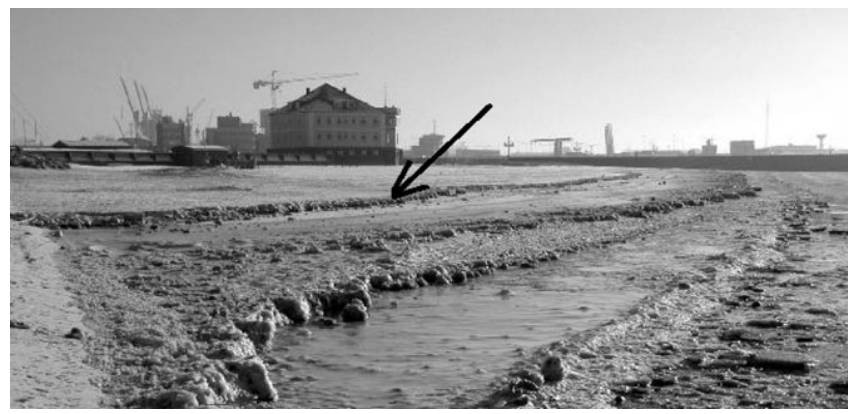

Fig. 1. View of the beach with several tidal ice terraces. The arrow indicates the position where the Figure 2 photograph was taken.
$1 \mathrm{~cm}$. The mass was $4.3-4.7 \mathrm{~kg}$, resulting in an average density of $\sim 700 \mathrm{~kg} \mathrm{~m}^{-3}$, assuming spherical shape.

Four balls were cut vertically (Fig. 3). The internal structure was similar in all cases: a spherical to oval inner core of white appearance, consisting of very porous ice platelets, eccentrically surrounded by a shell of solid dark ice. The transition between the two facies occurred within about $0.5 \mathrm{~cm}$. The inner cores measured $8-15 \mathrm{~cm}$ in diameter. The dark shells were 1 to $6 \mathrm{~cm}$ thick at their thinnest spot (near the top in the original position), varying between 6 and $8 \mathrm{~cm}$ at the thickest part (near the bottom).

The salinity and sediment content of 20 samples taken vertically and across two balls were measured. The salinity was practically zero in all cases $(<0.1 \mathrm{psu}$ (practical salinity units)). The sediment content, determined from vacuum filtration, however, showed a strong variation between the outer and inner facies, as well as horizontally and vertically. The largest sediment content of $150-190 \mathrm{~g} \mathrm{~kg}^{-1}$ was found near the bottom. It decreased to about $3 \mathrm{~g} \mathrm{~kg}^{-1}$ in the centre and increased again to values of $10-20 \mathrm{~g} \mathrm{~kg}^{-1}$ near the top. The horizontal sediment profile shows a smaller variation of $10-40 \mathrm{~g} \mathrm{~kg}^{-1}$ at the outermost positions. The sediment mostly consisted of fine sands, with no clay, but fine gravel and small organic remains (grass and reed) are also present in a few samples.

Density variations were derived from microcomputer tomography. The pore volume of the inner core was strongly connected within the ice matrix. It amounted to $\sim 50 \%$ which leads to a density of around $400 \mathrm{~kg} \mathrm{~m}^{-3}$. The density of the outer shell was close to the density of ice, without any significant pore structure.

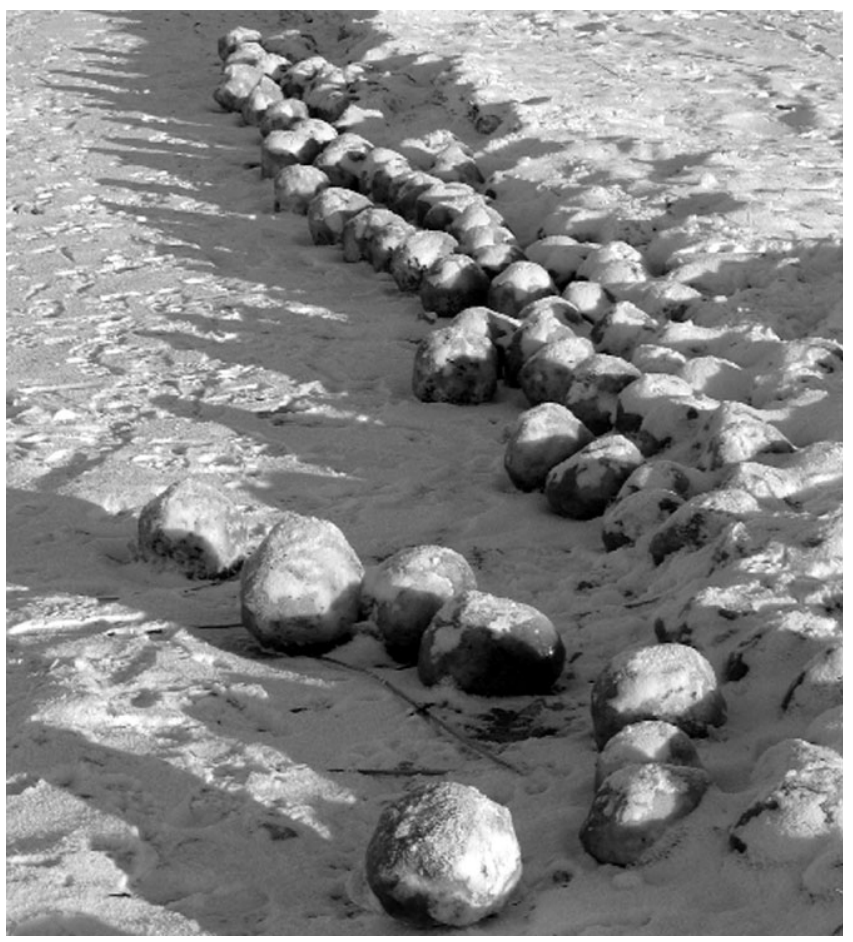

Fig. 2. Close-up of the uppermost tidal terrace with ice balls. The ice ball at the bottom is about $25 \mathrm{~cm}$ in diameter. 


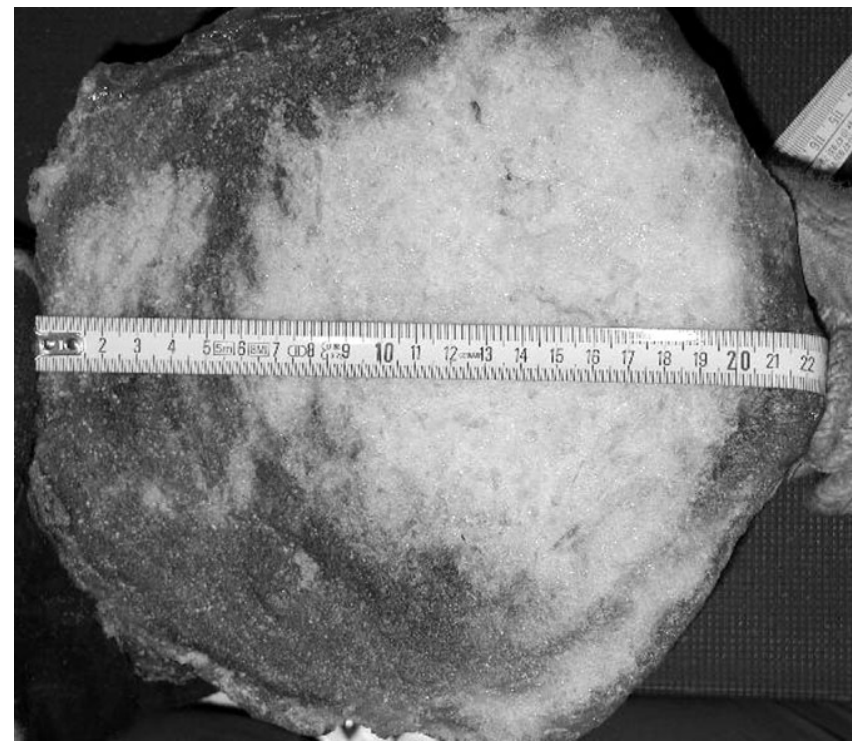

Figure 3. Close-up of one cross-section.

The Weser estuary is subject to strong tidal currents of up to 6 knots $\left(3 \mathrm{~m} \mathrm{~s}^{-1}\right)$, with a tidal range around $5 \mathrm{~m}$ dominated by semi-diurnal periods. The surface water has a low salinity $(<5 \mathrm{psu})$. After a cold period, temperatures rose abruptly from $-8^{\circ} \mathrm{C}$ to $0^{\circ} \mathrm{C}$ on 5 January, followed again by rapid cooling. An observatory of the German Weather Service (DWD) recorded light snowfall on the evening of 6 January, resulting in $3 \mathrm{~cm}$ of accumulated snow.

The ice balls were first discovered on 7 January, located at the uppermost tidal ice terrace and covered with a thin layer of fresh snow. In total, four tidal ice terraces were visible at that time, consisting of refrozen slush and larger chunks and floes of ice (Fig. 1). From water-level measurements of the Federal Maritime and Hydrographic Agency of Germany (BSH) it is evident that a spring tide occurred on the morning of 6 January. Water temperature near the surface of the river was close to, but still above, freezing.

Dynamic motion is involved in the formation of ice balls. The origin of their two distinctly different facies is less clear. From observations we deduce that the balls were formed during the night of 5/6 January. Although conditions were not sufficiently favourable to produce another event leading to similar ice balls in January and February, the first stages of their formation, which are comparable to the formation of ball ice and slush balls, were observed during repeated periods of cold weather.

The most important requirement seems to be the cooling of the beach surface below freezing during low tide. A rising water level leads to gradual coverage of the flat beach (slope $\sim 0.06$ ) with a layer of water only a few centimetres thick and up to $10 \mathrm{~m}$ wide. Due to the cooling, the water in contact with the beach surface then immediately freezes to form ice platelets. These then rise to the water surface and form slush. Snow precipitation during low tide increases the amount of slush. As small waves are always present, porous ball ice forms which is moved up the beach with increasing water level. Each time the balls are deposited higher on the beach by waves, the included water drains. At high tide, which lasts about 2 hours, the slush balls are more or less stationary and cool down to air temperature.The diameter of the balls is approximatley the height of the ice terrace, which consists of unconsolidated refrozen slush.

During calm periods larger waves, about $10-30 \mathrm{~cm}$ high, are produced by ship traffic, and produce surf at the beach, activating the second stage of formation. The surf leads to whirling up of sand in the water, and a small rocking movement of the balls. The water partly flushes the lower parts of the balls and deposits sand in the balls. Due to their low temperatures, the water freezes and seals the balls from further flushing. This leads to the abundance of sediment in the outer shell and low sediment content in the core, also producing the variation in thickness of the outer shell.

Assuming that the above formation process is correct, the question arises why this feature does not occur more often and why conditions do not always produce the same perfect ice balls. Obviously, temperatures several degrees below freezing are the most necessary condition. However, special dynamics in a fresh-water estuary combined with a large tidal range seem equally important. A third significant factor is the slope of the beach. As the German North Sea coast is mostly a km-wide tidal shallow, one might expect this phenomenon to occur along most of the beaches. Checking nearby tidal shallows showed, instead, that a flat slope rather leads to formation of floes, as the dynamic influence of waves is different. Steeper slopes, on the other hand, reduce the area that is cooled down during low tide, thus decreasing the amount of slush. Also, a stronger dynamic motion and mixing takes place, inhibiting slush consolidation. In conclusion, the special combination of the meteorological and oceanographic conditions at the beginning of January coinciding with the favourable beach properties and ship traffic have led to the formation of fragile ice balls, another impressive occurrence of ice in nature.

Alfred Wegener Institute for

Polar and Marine Research,

OLAF EISEN

P.O. Box 120161, D-27515 Bremerhaven,

Germany

JOHANNES FREITAG

CHRISTIAN HAAS

WOLFGANG RACK

GERIT ROTSCHKY

17 December 2003 JOCHEN SCHMITT

\section{REFERENGES}

International Association for Hydraulic Research (IAHS). 1980. Multilingual ice terminology. Addendum I. Budapest, Hungary, Research Centre for Water Resources. IAHS, section on ice problems.

United States Hydrographic Office (USHO). 1952. A functional glossary of ice termninology. Washington D.C., USHO Pub., no. 609. 